guidance to the surgeon who is inexperienced or is essaying an operation in a new field. All too often the essential practical points are missing and the only value of the book is as a mentor for the different world of surgical examinations. The first two volumes of this new work are of completely different stature and should be certain of immediate acceptance as a standard reference and a practical guide to surgeons of all degrees of experience.

The general pattern of the book, which is by multiple authors, is to give a guide to pre-operative treatment, followed by the steps of the operation in which the text mainly serves as an amplification of clear and accurate illustrations, each section being concluded by ample details of post-operative treatment. There are a number of general chapters, which are well planned to supplement the detailed chapters and established general principles. The chapter on 'Specimen Anastomosis of Hollow Viscera,' for example, by Sir Heneage Ogilvie, gives a concise and rational account of the general methods used in anastomoses and should prevent the surgical novitiate from being confounded by the minutiae of individual eponymous stitches.

It is inevitable that there should be a few points for adverse criticism but their relative insignificance serves to accent the high overall standard of the work. It is difficult, for example, to imagine at what stage in his career a surgeon would benefit from the chapter on the use of retractors. The use of polythene catheters is not mentioned in the chapter on Infusion and Transfusion, and while this method may be an over-worked fashion for many transfusions it is surely indispensable in the management of renal failure with concentrated glucose solutions. Many surgeons who work in remote hospitals where commercial infusion sets are unobtainable or prohibitively expensive would probably welcome advice about equipment and, in particular, a summary of the recent work on plastic and silicone rubber tubing. The very short section on volvulus of the caecum gives hemicolectomy as the treatment of choice and does not mention caecopexy, a much simpler procedure with fewer risks and a satisfactory end result.

These few criticisms are, however, trivial by comparison with the generally complete and soundly-established procedures which are so well described by such experts as Norman Tanner who contributes chapters on gastric surgery, and Milnes Walker who writes on operations for portal hypertension. It would appear from the first two volumes that this work will set an entirely new standard in books on operative surgery. Its price may be discouraging to some but does not seem excessive when it is considered that these beautifully printed and illustrated volumes should serve as a guide for many years.

\section{HUMAN DISEASE}

By A. E. Clark-Kennedy. Pp. 267. Harmondsworth: Penguin Books Ltd. 1957. 3s. 6d.

There is certainly a need for an explanation to the ordinary public of disease process, diagnostic procedure, and particularly some of the sequelae of illness. Dr. Clarke-Kennedy does this admirably in a form which can in general be well understoodprovided that it be remembered that the book is intended for 'The intelligent man in the street': three highly successful business men to whom the reviewer showed the book expressed themselves defeated by pages ro and i I! Dr. Clarke-Kennedy is to be congratulated on his work, as are the Publishers, who reproduce their usual excellence in this type of book which is a most useful addition to anyone's reading, and could do much to counteract the outpourings of some of the daily press.

A.E.C.

\section{THE THYROID}

\section{A Fundamental and Clinical Text}

Edited by Sidney C. Werner, M.D., Sc.D. Pp. xxii +978 , with 130 illustrations. London: Cassell and Co. Ltd. I955. $\oint_{7} 7 \mathrm{~s}$.

This beautiful book has been written by fifty-nine Americans and one Englishman (E. E. Pochin). Not all are primarily interested in the thyroid; the impressive list of contributors includes many names well known for their work in other fields as well: Burwell, Castle, Danowski, and the late John P. Peters, to mention only four. Marshalling the contributions of so many experts into a coherent whole cannot have been an easy task for the Editor, yet he appears to have been strikingly successful. He has adopted the course of writing a short introduction to each section, so as to put it in perspective and to provide a thread running throughout; this interesting expedient has much to commend it and the present reviewer would have liked these rather brief passages by Dr. Werner to have been longer, so as to provide even more continuity. As far as can be judged, he has been strikingly successful in avoiding constant repetition, the obvious danger when so many authorities co-operate.

In fact, this co-operation has produced a brilliant book. The sub-title 'A Fundamental and Clinical Text' is abundantly justified, for it is an accurate description. The whole panorama is here surveyed - the anatomy, physiology and biochemistry, the medical, psychiatric and surgical aspects, the laboratory and the clinical approach, all receive attention. The great body of new knowledge of thyroid function, made available by the use of radioiodine as an investigating tool in the last few years, is summarised.

Every section is reinforced with a large number of references. Even the most difficult and controversial subjects, such as that of thyroid carcinoma, are presented in what appears to be a rational and sensible manner.

The standards of production are extremely high, for the paper, printing and illustrations are all very good. This book attains a level of excellence rarely achieved, and appears to maintain it throughout. It sets an altogether new standard in its class, and the price is not excessive. 